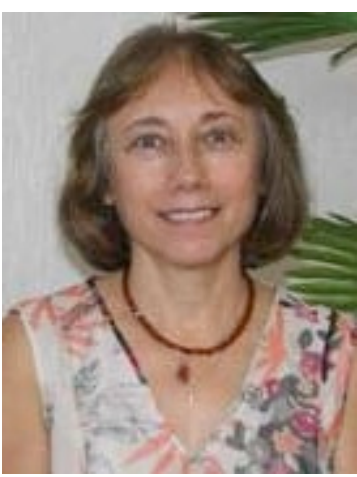

\title{
As demandas atuais de conhecimento na prática do cuidado em saúde mental
}

Nas ciências da Saúde, existe um reconhecimento mais ou menos unânime em relação ao que compete a cada um dos trabalhadores da equipe, embora os perfis profissionais venham se adequando ás realidades dos espaços de trabalho, e podem sofrer a influência de deficiências orçamentárias de órgãos responsáveis pela manutenção do setor saúde, de exigências do mercado e também das necessidades da população.

Os perfis profissionais de uns e outros em geral são distintos, embora compartilhem áreas formativas comuns e não é infrequente haver um certo grau de superposição entre elas, o que demanda a compreensão por parte dos componentes da equipe de saúde de que o objetivo maior da sua atuação é garantir o bem estar do usuário dos serviços. Para tanto, é necessário a aquisição de competências, isto é, pericia, aptidões específicas, idoneidade para desempenhar atividades ou intervir numa dada área. Na perspectiva educacional, distinguem-se as competências que são específicas e as que são transversais ou genéricas. As primeiras são motivo de atenção especial na formação, pois, caracterizam a profissão distinguindo-a de outras e cuja avaliação sanciona a outorga do título acadêmico que reconhece socialmente o desempenho da profissão(1).

Em geral as áreas de conhecimento que implicam intervenções na saúde, podem ser consideradas como áreas de "ciência aplicada"; nelas, as regras gerais são adaptadas às situações práticas e, as profissões cuja prática representa uma ciência aplicada, que envolve a dimensão afetiva das pessoas e suas relações com o mundo, deveriam valorizar o desenvolvimento de capacidades cognitivas e afetivas dos formandos, por meio de abordagens que possibilitem a interconexão das múltiplas dimensões envolvidas nas práticas laborais ${ }^{(2)}$.

No campo da Saúde, as concepções de ciência básica e aplicada, por vezes não se compatibilizam, uma vez que a tradição positivista da ciência básica dificulta o reconhecimento dos elementos transversais do comportamento humano conectados à dimensão biológica e que perpassam o processo saúde-doença. Contudo, a identificação de necessidades relacionadas ao componente subjetivo e social é tão importante quanto a identificação das vinculadas à dimensão biológica, já que as primeiras condicionam tanto a produção de saúde quanto o adoecimento das pessoas. Tal visão demanda um profissional aberto a inovações e à inserção de práticas não habituais no cuidado, sem perder de vista a garantia das evidências de sua efetividade ${ }^{(3)}$.

O presente e o futuro, requerem movimentos de indução à formação de profissionais de saúde com um perfil mais holístico em relação ao cuidado integral das pessoas, evidentemente esse é um processo em curso, mas que parece estar com dificuldades na geração de respostas com a rapidez necessária ao enfrentamento dos desafios que se apresentam no mundo do trabalho(3).

Dois artigos neste número desafiam o leitor a fazer o exercício de superar crenças aprendidas na sua formação e ampliar o horizonte dos seus conhecimentos, ambos tratam da inserção de Práticas Integrativas e Complementares, no tratamento e cuidado ao portador de doença mental e a usuários de substâncias psicoativas. No primeiro caso utilizou-se da prática de jogos teatrais em encontros, revelando ao final da pesquisa que estes influenciaram positivamente nas habilidades e competências sociais dos pacientes. No segundo, se avaliou a auriculoterapia como cuidado de enfermagem na redução do uso de maconha e cocaína, os autores concluem sobre a necessidade de incluir práticas de cuidado diversas das tradicionais na abordagem dos usuários.

Atualmente evidencia-se um aumento na procura de algum tipo de abordagem de saúde complementar, em 
função de sentimentos de descrença em relação aos tratamentos farmacológicos e psicológicos na saúde mental. Reduzir o estresse e melhorar os sintomas de ansiedade e de humor, têm sido alguns dos motivos do uso dessas práticas e também são as condições em que os benefícios têm se destacado(4).

As Práticas Integrativas e Complementares são consideradas recursos importantes no cuidado em saúde mental, pois são aceitas pelos usuários dos serviços de saúde e com isso favorecem a relação entre profissional e paciente, ampliam a autoconfiança do usuário e a aproximação com o familiar e a comunidade ${ }^{(5)}$. Talvez por não distanciar o tratamento do doente mental da mesma comunidade, pois são práticas amplamente utilizadas em outras alterações da saúde. Em razão disso é essencial que pesquisadores e profissionais se apropriem de conhecimentos que possibilitem compreender melhor os benefícios potenciais e as limitações desses procedimentos.

Um desafio da atualidade e com certeza crescente, para os profissionais e pesquisadores é a utilização das redes sociais criadas nos espaços virtuais, que atendem seus usuários na formação de grupos com objetivos benéficos como grupos de apoio e ajuda mútua de portadores de enfermidades específicas, ampliação de relacionamentos dentre outros, mas que também se prestam a ações escusas ou nocivas à saúde e integridade das pessoas.

Comunicações sociais geradas em comunidades virtuais, em Facebook e em outros meios tem despertado o interesse dos pesquisadores como fonte informações inclusive para aplicações em saúde e educação(6-7), porém elas não se prestam apenas a essas atividades, servem também ao marketing, e-commerce, empreendimentos de criatividade cultural, como veículo de distribuição na mídia e de entretenimento e inclusive para ativismo sociopolítico(7).

Um dos artigos apresentados traz o desafio, de compreender a formação no Facebook de um grupo de automutilação, com postagens textuais e de imagens, coletadas no período de um ano, que revelaram as características de identidade dos participantes, o contexto em que se dá essa prática e as atitudes de engajamento de seguidores.

Outro artigo aborda o protagonismo das famílias num Centro de Atenção Psicossocial (CAPS), mostram as autoras as dificuldades enfrentadas por esse grupo na luta pelos seus direitos, mesmo quando vinculados a associação de Pacientes, familiares e funcionários. Esse expediente configura ações de controle social sobre o cuidado que Ihes é propiciado A participação de familiares no tratamento, compartilhar experiências com outros familiares, trabalhadores da saúde e gestores propicia aos envolvidos, conhecimento de outros contextos e pode ser um caminho enriquecedor para todos no processo de reabilitação psicossocial dos sujeitos adoecidos.

Atualmente reivindica-se uma formação profissional menos técnica e mais crítica e politizada, com a inserção de discussões pouco contempladas nos espaços de ensino superior, como o aprofundamento sobre temas como a reforma sanitária, reforma psiquiátrica, assistência social, direitos humanos, cidadania, movimentos sociais e conselhos de controle social, buscando sensibilizar os graduandos e fazer com que se percebam como parte desse processo e afinados com as políticas sociais ${ }^{(8)}$. Nas Associações em que há participação de usuários, eles estão exercendo a prerrogativa de monitorar e avaliar os serviços que utilizam.

As expectativas em relação ao ingresso à universidade podem interferir na transição do aluno do Ensino Médio para o Ensino Superior, ou seja, quanto maior for o nível de expectativas, maiores são as inferências geradas pelos estudantes a respeito das mesmas. Isso pode resultar em ações focadas no desempenho acadêmico e, consequentemente, na percepção de um ambiente reforçador de pensamentos, sentimentos e comportamentos que inibem, limitam ou facilitam a adaptação ao novo meio social( ${ }^{(9)}$ estudiosos ${ }^{(10)}$ ressaltaram a dinâmica existente nesse contexto entre recursos pessoais e institucionais, os quais interagem simultaneamente e interferem no desempenho do estudante alterando sua percepção de bem-estar físico e psicológico.

Aansiedade entre estudantes universitários é um fenômeno que deve ser reconhecido para intervir precocemente, quando atinge o nível de sintomas físicos e psíquicos fora de controle, pois em níveis mais altos a ansiedade pode afetar de forma significativa a formação da identidade do estudante e a sua qualidade de vida(11), assim como levar a comportamentos prejudiciais à sua saúde e integridade. Estudantes muitas vezes se sentem vulneráveis na gestão do volume crescente de informações que a vida universitária acarreta e também com o planejamento da carreira profissional, além da vivência de estresse decorrente de certas peculiaridades do ensino-aprendizagem da profissão. Somado a isso, o estudante, convive com a busca de independência e autonomia em relação aos pais, com os conflitos entre compatibilizar os trabalhos acadêmicos com atividades de lazer, além dos conflitos ligados aos relacionamentos afetivos ${ }^{(12)}$.

Estudos $^{(12-13)}$ realizados com estudantes da área da saúde, particularmente os que tem contato direto com usuários dos serviços de saúde (médicos e enfermeiros) tem verificado o impacto do estresse e das habilidades sociais na experiência acadêmica de estudantes e abalizaram que a falta de habilidades sociais dos alunos para enfrentar as situações interpessoais sociais percebidas como de risco social, está relacionado ao estresse. Tais 
evidências endossam as preocupações quanto ao desempenho acadêmico, à saúde e ao bem estar psicossocial do universitário.

O envolvimento com substâncias psicoativas é um comportamento esperado nesse grupo composto por adolescentes e adultos jovens. No Brasil, os problemas relacionados ao consumo de substâncias psicoativas nessa população são preocupantes. Pesquisa, desenvolvida com populações de universitários na década de noventa(14) indicaram que álcool e o tabaco eram as substâncias mais consumidas com alta prevalência do uso nos últimos 12 meses, de $82,3 \%$ de álcool, $29,6 \%$ de tabaco e $30,6 \%$ de "drogas ilícitas" estas últimas, mostraram uma prevalência de uso de 38,1\% na vida, 26,3\% nos últimos 12 meses e 18,9 \% nos últimos 30 dias, (dados na área das ciências biológicas). $\mathrm{O}$, uso de "drogas ilícitas" foi maior entre alunos do sexo masculino. Em pesquisa semelhante realizada posteriormente, com o mesmo questionário(15), avaliou-se o comportamento dos alunos de graduação também da área de ciências biológicas, em relação ao uso de álcool e drogas". Observou-se que os usuários de tabaco e de "drogas" se dedicavam mais às atividades socioculturais e gastavam menos tempo com atividades acadêmicas em relação aos não usuários. Tais resultados corroboraram estudo anterior ${ }^{(16)}$ e mostraram que os alunos da área de ciências biológicas devem merecer um enfoque diferenciado em relação ao uso de álcool e de outras drogas pois, futuramente, serão os que levarão as noções básicas de saúde à comunidade.

Assim, é importante conhecer o padrão de consumo, as atitudes e o conhecimento desse grupo em relação ao consumo de álcool, tabaco, "drogas ilícitas" e "medicamentos. Estudo(17) encontrou correlação entre o aumento do uso de tabaco e de "drogas" quando os alunos estavam mais cansados, estressados, deprimidos ou em festas e o uso de álcool foi maior quando os alunos estavam em festas ou durante os fins de semana e horários livres. Essa observação mostrou que os usuários dessas substâncias ao estarem fora de casa e, mais expostos ao uso aumentavam o consumo. Alunos que não possuíam ou praticavam religião e os de rendas familiar mais elevada, mostraram-se mais expostos ao uso. Os dados revelaram a necessidade de direcionar de forma diferenciada a política de conscientização e prevenção para essas populações, pois pode ser mais bem sucedida do que uma ação que aborde igualmente a todos os alunos.

Estudo na população de universitários no Nordeste do Brasil(18) mostrou que o maior consumo de álcool, especialmente o abuso, ocorreu entre os estudantes do sexo masculino, os de maior idade, os fumantes. Também evidenciou que os estudantes conheciam as formas de transmissão de DST e sobre anticoncepcionais, porém havia desinformação sobre a AIDS e isso foi mais frequente entre os que abusavam de álcool, o que potencializa riscos, uma vez que o abuso de álcool se correlaciona com práticas sexuais não seguras. O mesmo estudo indicou o abuso do álcool associado à exposição à publicidade em muitos meios de comunicação, demonstrando a sua influência no consumo de bebidas alcoólicas.

Dois estudos abordam o tema mostrando que os cenários não mudaram, o jovem universitário continua utilizando substâncias psicoativas e de forma abusiva, expondo-se a riscos de toda sorte. Talvez tenha chegado a hora, aliás já passou da hora de fazer estudos de intervenção entre os estudantes, que evidenciem formas efetivas de incentivo ao consumo sensato, para minimizar os riscos do consumo abusivo, situando o uso de substâncias numa expectativa de ser um uma forma de recreação.

O uso de crack entre mulheres é abordado por um artigo, de forma pertinente por se tratar de um tema aliado à marginalidade e criminalidade, atributos em geral conferidos a seus usuários, assim como as práticas sexuais de risco(19). Existe já instituído o estigma atribuído a essa população, construído em parte pela discriminação veiculada maciçamente pelos meios de comunicação de massa em torno do uso dessa droga, o que traz maiores dificuldades, a esse grupo na busca por serviços de saúde ${ }^{(20)}$.

As pesquisas escassas na perspectiva de gênero e de vulnerabilidade inviabilizam a categorização das mulheres como um grupo para a constituição de programas terapêuticos mais adequados e sensíveis às suas prioridades e necessidades, caracterizando a mulher como um ser marginalizado, inclusive no campo das dependências. No entanto, de forma crescente percebe-se a necessidade de realizar grupos terapêuticos distintos para homens e mulheres ${ }^{(20)}$, provavelmente, devido ao estigma social que as mulheres sentem em suas exposições nos grupos mistos $^{(21)}$. O conjunto de referências de estudos sobre o tema mais o apresentado neste número, indica a premência, de introduzir inovações nas práticas sociais e de saúde para acessar esse público.

Foram bem diversificados e complexos os temas abordados, no entanto eles são relevantes e atuais, a expectativa é de que a leitura dos artigos, atualize os conhecimentos, cause inquietação e leve os profissionais de saúde, educadores e pesquisadores à reflexão e estimule seu interesse em aprofundar o seu saber e a sua criatividade no desenvolvimento de programas e projetos dedicados a grupos da população semelhantes aos estudados neste número. 


\section{Referências}

1. Baños JE. Cómo fomentar las competencias transversales en los estudios de Ciencias de la Salud: una propuesta de actividades. Educ Médica. 2005;8(4):216-25.

2. Gauthier C, Tardif M. A pedagogia: teorias e prática da antiguidade aos nossos dias. Petropolis. Rio de Janeiro: Vozes; 2010.

3. Pinheiro R, Mattos RA, organizadores. Os sentidos da integralidade na atenção e no cuidado à saúde. Rio de Janeiro: UERJ/IMS, ABRASCO; 2006

4.Asher GN, Gerkin J, Gaynes BN. Complementary Therapies for Mental Health Disorders. Med Clin N Am. 2017;101(5):847-64.

5.Stussman BJ, Black LI, Barnes PM, Clarke TC, Nahin RL. Wellness-related use of common complementary health approaches among adults: United States, 2012. Natl Health Stat Rep. 2015;(85):1-12.

6.Separavich MA,Canesqui AM. Análise das narrativas sobre a menopausa de um site brasileiro da internet. Interface. (Botucatu) 2012;16(42):609-22.

7.Castells M. Redes de indignação e esperança: movimentos sociais na era da internet. Rio de Janeiro: Zahar; 2013.

8. Andrade e Silva C, Yamamoto OH. As Políticas Sociais na Formação Graduada do Psicólogo no Piauí. Psicologia: Ciênc Profissão. 2013;33(4):824-39.

9.Fernandes EP, Almeida LS. Expectativas e vivências acadêmicas: Impacto no rendimento dos alunos do do $1^{\circ}$ ano. Psychologia. 2005;40(1):267-78.

10.Cunha MS, Carrilho DM. O processo de adaptação ao Ensino Superior e o rendimento acadêmico. Psicol Esc Educac. 2005;9(2):215-24.

11. Gultekin BK, Dereboy IF. Th e Prevalence of Social Phobia, and its Impact on Quality of Life, Academic Achievement, and Identity Formation in University Students. Turkish J Psychiatry. 2011;22(3):150-8.

12. Galindo SB, Moreno IM, Muñoz JG. Prevalencia de ansiedad y Depressión em uma población de Estudiantes universitários: Factores acadêmicos y sociofamiliares asociados. Clín Salud. 2009;20(2):177-87.

13.Furtado ES, Falcone EMO, Clark C. Avaliação do estresse e das habilidades sociais na experiência acadêmica de estudantes de Medicina de uma universidade do Rio de Janeiro. Interação Psicol. 2003;7(2):43-51.

14. Andrade AG, Queiroz S, Villaboim RCM, César CLG,Alves MCGP, Bassit AZ, et al. Uso de álcool e drogas entre alunos de graduação da Universidade de São Paulo. Rev ABP-APAL.1997;19(2):53-9.

15. Barría ACR, Queiroz S, Nicastri S, Andrade AG. Comportamento do universitário da área de biológicas da Universidade de São Paulo, em relação ao uso de drogas. Rev Psiquiatr Clín. (São Paulo) 2000;27(4):215:24.

16. Stempliuk VA, Barroso LP, Andrade, AG, Nicastri, S,Malbergier A. Comparative study of drug use among undergraduate students at the university of São Paulo- São Paulo campus in 1996 and 2001. Rev Bras Psiquiatr. 2005;27(3):185-93.

17.Silva LVER, Malbergier A, Stempliuk VA, Andrade AG. Fatores associados ao consumo de álcool e drogas entre estudantes universitários. Rev Saúde Pública. 2006;40(2):280-8.

18. Pedrosa AAS, Camacho LAB , Passos SRL, Oliveira RVC .Consumo de álcool entre estudantes universitários. Cad Saúde Pública. 2011;27(8):1611-21.

19. Seleghim MR. et al. Vínculo familiar de usuários de crack atendidos em uma unidade de emergência psiquiátrica. Rev. Latino-Am. Enfermagem. [Internet] 2011 [Acesso 24 ago 2018];19(5). Disponível em: http://www.scielo.br/pdf/ rlae/v19n5/pt_14.pdf.

20. Venosa PAS. Grupos psicoterapêuticos de mulheres dependentes químicas: questões de gênero implicadas no tratamento. Rev SPAGESP. 2011;12(1):56-6.

21. Ramiro FS, Padovani RC, Tucci AM. Consumo de crack a partir das perspectivas de gênero e vulnerabilidade: uma revisão sobre o fenômeno. Saúde Debate. [Internet]. 2014 [Acesso 24 ago 2018];38(101). Disponível em: https:// doi.org/10.5935/0103-1104.20140035

Margarita Antonia Villar Luis

Editor Chefe da SMAD, Revista Eletrônica Saúde Mental Álcool e Drogas, Professor Titular da Escola de Enfermagem de Ribeirão Preto, Universidade de São Paulo, Centro Colaborador da OPAS/OMS para o Desenvolvimento da Pesquisa em Enfermagem, Brasil, e-mail: margarit@eerp.usp.br 